\title{
CLINICAL STUDY OF MANAGEMENT OF VARICOCELE
}

\author{
Immadi Chandra Sekhar1, Anday Venkata Mohana Rao ${ }^{2}$
}

${ }^{1}$ Assistant Professor, Department of Urology, Andhra Medical College, King George Hospital, Visakhapatnam, Andhra Pradesh. ${ }^{2}$ Assistant Professor, Department of Urology, Andhra Medical College, King George Hospital, Visakhapatnam, Andhra Pradesh.

\section{ABSTRACT}

\section{BACKGROUND}

Varicocele is a major identifiable cause of male infertility.

Aim- Effectiveness of laparoscopic varicocelectomy in management of infertility and pain.

Study Design- This is a prospective study, which included 44 cases of Varicocele over a period of 24 months between December 2008 and November 2010 at King George Hospital, Visakhapatnam.

\section{MATERIALS AND METHODS}

This study was conducted at Department of Urology, King George Hospital, Visakhapatnam between December 2008 and November 2010. Physical examination, semen analysis, hormonal evaluation and colour Doppler scrotum were performed for each patient. Laparoscopic varicocelectomy was performed and were followed up after 3, 6 and 12 months along with their semen analysis reports.

\section{RESULTS}

Of the 44 cases evaluated, highest age incidence is in the age group of 20 - 30 years of age with a total of $45.5 \%$ of cases. Predominantly, varicocele is seen on the left side consisting of $77.27 \%$ of cases. $53.84 \%$ of cases had grade 2 varicocele. Sperm count and motility improved after laparoscopic varicocelectomy.

\section{CONCLUSION}

A correct treatment may lead to resolution of symptoms and improvement in sperm count in subfertile patients. There are various modalities of treatment for varicocele, but laparoscopic varicocelectomy is more appropriate and advantageous in various aspects.

\section{KEYWORDS}

Varicocelectomy, Pampiniform Plexus, Colour Doppler Scrotum, Internal Inguinal Ring, Spermatic Cord, Visual Analogue Scale.

HOW TO CITE THIS ARTICLE: Sekhar IC, Rao AVM. Clinical study of management of varicocele. J. Evolution Med. Dent. Sci. 2017;6(32):2609-2614, DOI: 10.14260/Jemds/2017/564

\begin{abstract}
BACKGROUND
Varicocele is an important cause of male infertility. It is often associated with pain and abnormal testicular histology and semen. It is one of the diseases of male urogenital tract. It is defined as an abnormal dilatation of the veins of the pampiniform plexus in the spermatic cord. It occurs predominantly on the left side, but isolated right-sided and bilateral varicoceles are seen. Typically, it is idiopathic, although acquired lesions in association with benign and malignant retroperitoneal disease do exist.

Varicocele is found in approximately $15 \%$ of adult males, but the incidence could go as high as $40 \%$ in patients attending infertility clinics and up to $80 \%$ in those with secondary infertility.[1-3] It is well known that the ipsilateral testis in patients with varicoceles is smaller than the other side. $[4,5]$ This is more evident in teenage boys owing to the rapid increase in the testicular volume. Haans et al[6]
\end{abstract}

Financial or Other, Competing Interest: None.

Submission 14-03-2017, Peer Review 09-04-2017,

Acceptance 13-04-2017, Published 20-04-2017.

Corresponding Author:

Dr. Immadi Chandra Sekhar,

Harshitha Hospital, 9-7-289,

Sai Ramnagar,

Lane opposite Vaibhav Jewelleries,

Gajuwaka, Visakhapatnam- 530026,

Andhra Pradesh.

E-mail:vanajasekhar@yahoo.com

DOI: $10.14260 /$ jemds $/ 2017 / 564$

(c) (i) $९$ demonstrated that the loss of testicular volume in patients with varicoceles was associated with decreased sperm count.

Varicocele is associated with impairment in spermatogenesis mainly in the form of low count (oligozoospermia), decreased sperm motility (asthenozoospermia) and abnormal sperm morphology (teratozoospermia) in infertile males presenting with varicoceles. These abnormalities can occur in isolation or in combination (known as oligoasthenoteratospermia or OAT syndrome). This effect was first described in 1965 by MacLeod,[7] who described the above seminal abnormalities in patients with varicocele.

The American Urology Association Recommends Varicocele Treatment in Males who meet the following Criteria[8]-

- Grade II or III varicoceles.

- Abnormal semen parameters.

- The couple has a documented infertility.

- The female counterpart has a normal or potentially correctable cause of infertility.

Although, no well-controlled series has been reported, the surgical repair of varicoceles in selected infertile patients appears to augment the percentage of motile spermatozoa, improve the total spermatozoa count and may be related to increased fertility. In a randomised controlled clinical trial, Al-Kandari et al ${ }^{[9]}$ showed that subinguinal microsurgery was more effective than open inguinal or laparoscopic 
varicocelectomy in terms of improvement in semen quality and pregnancy outcome.

\section{Advantages of Laparoscopic Varicocele Surgery over other Techniques include}

- Accurate identification of all the veins as the surgery is done under magnification during laparoscopy.

- Varicoceles from both sides of the body can be corrected at the same time without the need for further surgical incisions.

- $\quad$ Rapid recovery from surgery with minimal pain as the small $5 \mathrm{~mm}$ wounds causes minimal trauma to tissue.

- Patients can be discharged a few hours after surgery and they can return to work within 48 to 72 hours.

- $\quad$ Specialised equipment like microscope and surgical expertise in microscopic surgeries is not needed. It is cheaper than microscopic varicocelectomy, but equally effective.

Laparoscopic varicocelectomy have broadened the therapeutic options for varicocele. Their clinical significance is yet to be confirmed. Hence, this study aims at a definitive look, into varicocele and effectiveness of laparoscopic varicocelectomy.

\section{Aim of the Study}

Effectiveness of laparoscopic varicocelectomy in management of infertility and pain.

\section{MATERIALS AND METHODS}

This is a prospective study including a total of 44 cases of varicocele who attended Department of Urology, Andhra Medical College, King George Hospital, Visakhapatnam, Andhra Pradesh over a period of 24 months between December 2008 and November 2010.

\section{Inclusion Criteria}

- Patients who attended to the Urology Clinic with symptomatic varicocele, i.e. pain.

- Patients with asymptomatic varicocele with history of infertility.

- Unilateral or bilateral varicocele.

- $\quad$ Recurrent varicocele.

\section{Exclusion Criteria}

- Secondary varicoceles, which are already diagnosed or diagnosed during the study.

- When patients are associated with other recognisable causes of infertility.

- Patients more than 50 years of age and less than 10 years of age.

- Patients who lost for followup for at least 1 year.

\section{Method of Evaluation}

Physical examination, semen analysis and hormonal evaluation were performed for each patient. In the physical examination, laterality (unilateral or bilateral) and the grade (Grade I to III) of varicocele were determined by inspection and palpation with the patient in an upright position. Pain which is described by the patient has been given points according to visual analogue scale [VSA] (Figure 1).
The Grade of Varicocele was classified based on the Criteria Proposed by Pryor and Howards. The Criteria were-

Grade I (Small)- Detected by palpation with difficulty, but increased by Valsalva's manoeuvre.

Grade II (Moderate)- Detected easily by palpation without Valsalva's manoeuvre.

Grade III (Large)- Detected visually from a distance.

Semen samples were collected by masturbation after 2 - 5 days of abstinence and were tested for semen volume, motility and total count. Semen analysis was conducted at least three times and from among these the data from the analysis showing the highest sperm concentration were selected for analysis.

Patients with absent or low-volume ejaculate suggesting retrograde ejaculation or ejaculatory duct obstruction and patients with physical features, semen and hormonal data suggesting male infertility due to genetic factors were not included in the present study.

\section{Colour Doppler of the Scrotum is done}

Ultrasound whole abdomen is done to rule out any masses. Other investigations like complete blood picture and chest $\mathrm{x}$ ray were done.

\section{Procedure}

Patients were selected for laparoscopic varicocelectomy after providing informed consent; 3 laparoscopic ports were used. The patient emptied his bladder to reduce risk of bladder puncture before surgery. The patient was placed in head down position at about 10 degrees. Veress needle inserted and the abdominal cavity was insufflated by $\mathrm{CO} 2$ to a maximum of $13 \mathrm{mmHg} ; 10 \mathrm{~mm}$ port inserted. The other two 5-mm ports were placed in the right and left lower quadrants under laparoscopic vision.

The peritoneum overlying the internal spermatic vessels was incised longitudinally about $2-3 \mathrm{~cm}$ superior to the internal ring over a distance of about $3 \mathrm{~cm}$ (Figure 2). Blunt dissection was used to isolate the bunch of spermatic vessels (Figure 3). The bunch of spermatic vessels was divided using Ligasure or Harmonic scalpel (Figure 4) or by applying clips (Figure 5). The spermatic veins are isolated from artery and are ligated with clips or harmonic scalpel, but never with cautery especially with monopolar.

At the end of the procedure, the rectus at the $10-\mathrm{mm}$ port and the skin were sutured with prolene. And patients were discharged on post-operative day 2. Post-operative followup of these patients was done after 7 days for suture removal and on 3 months, 6 months and 1 year's period along with their semen analysis reports.

\section{Ethics}

We have taken consent from Ethical Committee of our Institution.

\section{RESULTS}

A total of 44 cases were studied.

\section{Table 1 shows the Age Incidence}

Average age in our study is 30 years. Highest age incidence noted in the age group of $20-30$ years of age group 
consisting of $45.5 \%$ of cases followed by the age group of 30 40 years of age group. Least incidence noted in the age group of 40 - 50 years of age with $4.4 \%$ of cases.

Table 2 shows the Percentage of Cases Depending on Laterality

Predominantly, varicocele is seen on left side consisting of $77.27 \%$ of cases followed by bilateral varicocele which constitute $18.2 \%$. Unilateral right-sided varicocele is extremely rare. Only 2 cases among 44 cases (4.5\%) is seen.

\section{Table 3 shows Grade of Varicocele}

Total no. of cases is 44 , among them 8 patients have bilateral varicocele. Thus, total no. of varicocele became 52 , of which $20(38.46 \%)$ varicoceles are graded as III, 28 (53.84\%) varicoceles are graded as II and 4 as grade I (7.7\%).

\section{Table 4 shows Complaints with Varicocele}

In our study, the patients attended Urology Department with complaints of pain and discomfort associated with varicocele and infertility. Among 44 patients 16 patients (36.4\%) came with complaints of pain and persistent discomfort, 16 patients (36.4\%) presented with infertility and remaining 12 (27.2\%) presented with both complaints.

\section{Pain is assessed using Visual Analogue Scale}

In our study, a total number of patients presented with complaints of pain to the Urology department were 28. These patients were examined and they were given visual analogue pain points after thorough examination according to predetermined scale.

And followup of these patients is done at 3 months, 6 months and 1 year after surgery.

\section{Table 5 shows Symptomatic Relief in Patients with Pain}

Of the 28 cases who presented with pain, in 12 patients (42.9\%) pain was completely resolved. There is partial improvement in pain in 8 patients $(28.6 \%)$. Out of the remaining 8 patients, pain persisted in 4 patients $(14.25 \%)$ and pain worsened in 4 patients $(14.25 \%)$.

\section{Table 6 shows Improvement of Sperm Count}

Average sperm count pre-operatively is 24.5 millions $/ \mathrm{mL}$. After 3 months post-operatively, sperm count improved to 35.2 millions $/ \mathrm{mL}$. After 6 months, it improved to 41.59 millions/mL and after 1 year it is 49.86 millions $/ \mathrm{mL}$ which is nearly double the pre-operative count.

\section{Table 7 shows Improvement in Average Motility}

Average sperm motility in pre-operative period is $28.18 \%$. After 3 months post-operative period, it improved to $39.77 \%$. After 6 months, average sperm motility is $51.32 \%$ and at 1 year it improved to $57.95 \%$.

\begin{tabular}{|c|c|c|}
\hline Age in Years & Total No. & Percentage \\
\hline $10-20$ & 6 & 13.7 \\
\hline $20-30$ & 20 & 45.5 \\
\hline $30-40$ & 16 & 36.4 \\
\hline $40-50$ & 2 & 4.4 \\
\hline \multicolumn{3}{|c|}{ Table 1. Age Incidence } \\
\hline
\end{tabular}

\begin{tabular}{|c|c|c|}
\hline Side & Number & Percentage \\
\hline Bilateral & 8 & 18.2 \\
\hline Left & 34 & 77.27 \\
\hline Right & 2 & 4.5 \\
\hline \multicolumn{2}{|c|}{ Table 2. Laterality } \\
\hline
\end{tabular}

\begin{tabular}{|c|c|c|}
\hline Grade & No. & Percentage \\
\hline I & 4 & $7.7 \%$ \\
\hline II & 28 & $53.84 \%$ \\
\hline III & 20 & $38.46 \%$ \\
\hline \multicolumn{3}{|c|}{ Table 3. Grade of Varicocele } \\
\hline
\end{tabular}

\begin{tabular}{|c|c|c|}
\hline Complaint & No. & Percentage \\
\hline Pain & 16 & 36.4 \\
\hline Infertility & 16 & 36.4 \\
\hline Both & 12 & 27.2 \\
\hline \multicolumn{2}{|c|}{ Table 4. Complaints with Varicocele } \\
\hline
\end{tabular}

\begin{tabular}{|c|c|c|}
\hline Pain & No. & Percentage \\
\hline $\begin{array}{c}\text { Completely } \\
\text { resolved }\end{array}$ & 12 & 42.9 \\
\hline Partial response & 8 & 28.6 \\
\hline Persistent pain & 4 & 14.25 \\
\hline Worsened & 4 & 14.25 \\
\hline \multicolumn{3}{|c|}{ Table 5 }
\end{tabular}

\begin{tabular}{|c|c|c|c|c|}
\hline $\begin{array}{c}\text { Average } \\
\text { Sperm } \\
\text { Count }\end{array}$ & $\begin{array}{c}\text { Pre- } \\
\text { op }\end{array}$ & $\begin{array}{c}\text { 3 } \\
\text { Months } \\
\text { Post-op }\end{array}$ & 6 Months & $\begin{array}{c}\text { 1 Year } \\
\text { Post-op }\end{array}$ \\
\hline & $\begin{array}{c}24.5 \\
\text { million }\end{array}$ & $\begin{array}{c}35.2 \\
\text { million }\end{array}$ & $\begin{array}{c}41.59 \\
\text { million }\end{array}$ & $\begin{array}{c}49.86 \\
\text { million }\end{array}$ \\
\hline \multicolumn{6}{|c|}{ Table 6. Improvement in Average Sperm Count } \\
\hline
\end{tabular}

\begin{tabular}{|c|c|c|c|c|}
\hline $\begin{array}{c}\text { Average } \\
\text { Motility }\end{array}$ & Pre-op & $\begin{array}{c}\text { 3 } \\
\text { Months } \\
\text { Post-op }\end{array}$ & $\begin{array}{c}\text { 6 Months } \\
\text { Post-op }\end{array}$ & $\begin{array}{c}\text { 1 Year } \\
\text { Post-op }\end{array}$ \\
\hline \multicolumn{4}{|c|}{ Table 7. Improvement in Average Motility } \\
\hline
\end{tabular}

\begin{tabular}{|c|c|c|}
\hline & Our Study & Hitoshi et al \\
\hline Left & $77.3 \%$ & $79 \%$ \\
\hline Right & $4.5 \%$ & $0 \%$ \\
\hline Bilateral & $18.2 \%$ & $21 \%$ \\
\hline \multicolumn{3}{|c|}{ Table 8. Laterality } \\
\hline
\end{tabular}

\begin{tabular}{|c|c|c|}
\hline & Our Study & Onozawa et al \\
\hline Grade I & $7.6 \%$ & $15.6 \%$ \\
\hline Grade II & $53.8 \%$ & $50 \%$ \\
\hline Grade III & $38.46 \%$ & $34.4 \%$ \\
\hline \multicolumn{2}{|c|}{ Table 9. Grade Wise Incidence of Varicocele } \\
\hline
\end{tabular}

\begin{tabular}{|c|c|c|}
\hline Pain & Our Study & Amagan et al \\
\hline Improved & $71 \%$ & $79.2 \%$ \\
\hline Failure & $29 \%$ & $20.8 \%$ \\
\hline Table 10. Pain Response after Varicocelectomy \\
\hline
\end{tabular}




\begin{tabular}{|c|c|c|c|c|}
\hline $\begin{array}{c}\text { Average } \\
\text { Sperm } \\
\text { Density }\end{array}$ & Pre-op & $\begin{array}{c}\text { 3 } \\
\text { Months } \\
\text { Post-op }\end{array}$ & $\begin{array}{c}\text { 6 Months } \\
\text { Post-op }\end{array}$ & $\begin{array}{c}\text { 1 Year } \\
\text { Post-op }\end{array}$ \\
\hline & $\begin{array}{c}24.5 \\
\text { million }\end{array}$ & $\begin{array}{c}35.2 \\
\text { million }\end{array}$ & $\begin{array}{c}41.59 \\
\text { million }\end{array}$ & $\begin{array}{c}49.86 \\
\text { million }\end{array}$ \\
\hline \multicolumn{3}{|c|}{ Table 11. Average Sperm Density after Varicocelectomy } \\
\hline
\end{tabular}

\begin{tabular}{|c|c|c|c|c|}
\hline $\begin{array}{l}\text { Average } \\
\text { Motility }\end{array}$ & $\begin{array}{c}\text { Pre- } \\
\text { op }\end{array}$ & $\begin{array}{c}\text { 3 } \\
\text { Months } \\
\text { Post-op }\end{array}$ & $\begin{array}{c}\text { 6 Months } \\
\text { Post-op }\end{array}$ & $\begin{array}{c}\text { 1 Year } \\
\text { Post-op }\end{array}$ \\
\hline \multicolumn{6}{|c|}{$28.18 \%$} & $39.77 \%$ & $51.32 \%$ & $57.95 \%$ \\
\hline \multicolumn{3}{|c|}{ Table 12. Average Sperm Motility after Varicocelectomy } \\
\hline
\end{tabular}

\begin{tabular}{|c|c|c|}
\hline Sperm Parameters & Pre-op & Post-op \\
\hline Density & 33 million & 55 million \\
\hline Motility & $36.4 \%$ & $60 \%$ \\
\hline Table 13. Sperm Parameters in Gouda El-Labban Study \\
\hline
\end{tabular}

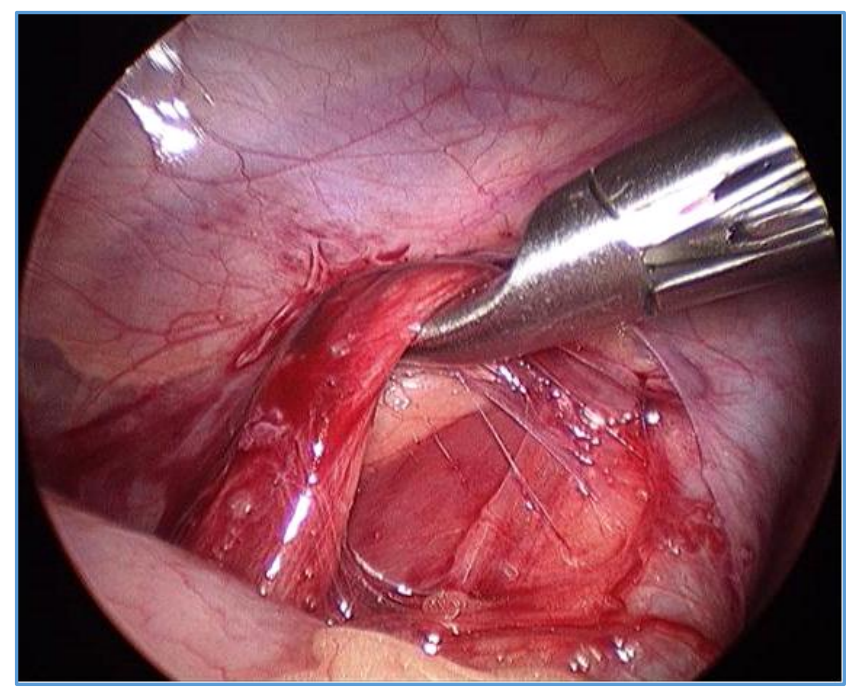

Figure 3. Isolating Testicular Vessels

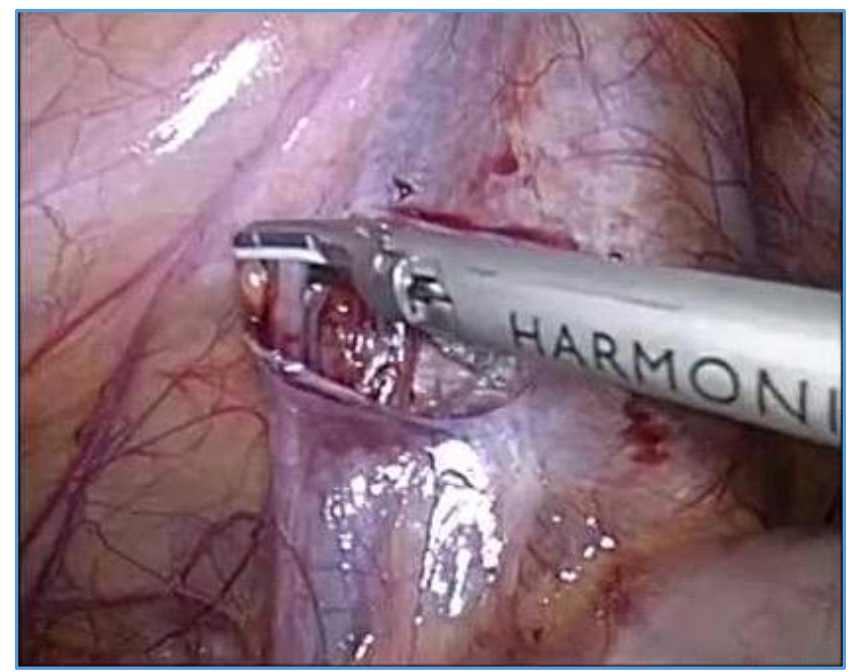

Figure 4. Varicocelectomy using Harmonic Scalpel

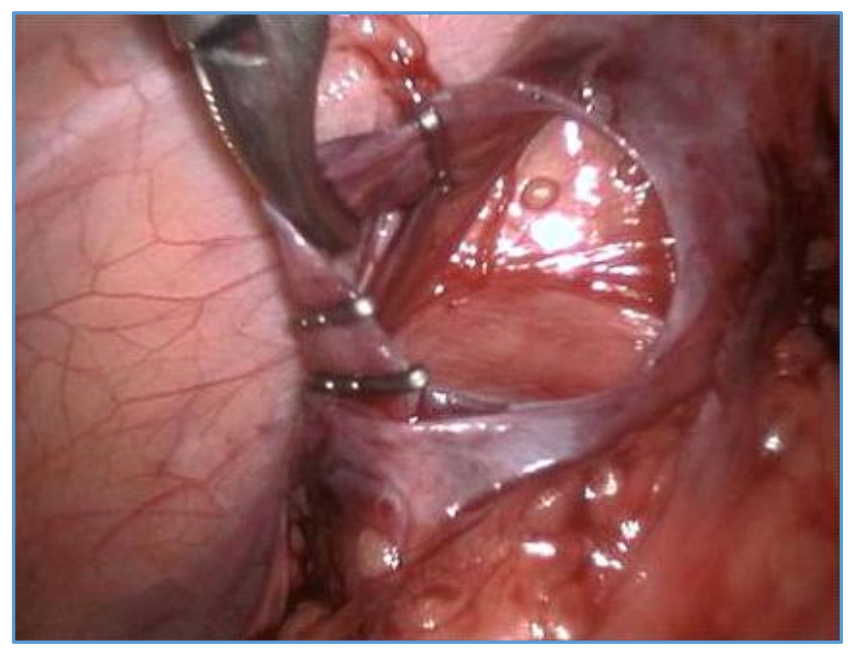

Figure 5. Varicocelectomy using Clips

\section{DISCUSSION}

The incidence of varicocele has been reported as comprising one-third of infertile men, but in only one-fifth of patients, varicocele is caused for infertility. Most males with varicocele are fertile. All these factors contribute to difficulties in the evaluation of therapeutic intervention of varicocele.

Figure 2. Per-operative Picture of Laparoscopic Varicocelectomy- Isolating Testicular Veins 
Although an adequate consensus is not available, based on the literature and clinical experiences supporting its benefit, varicocelectomy is the chosen treatment of varicocele in many institutes.

In the present study, screening of varicocele was conducted by palpation and colour Doppler scrotum. It is widely accepted that varicocelectomy improves semen parameters in patients with varicocele with a $60 \%-80 \%$ recovery rate. Schlesinger et al reviewed 16 studies that assessed the effect of varicocelectomy on sperm density and reported that post-operative significant improvements were demonstrated in 12 studies.[10]

Schlesinger et al also reported that sperm motility statistically improved after varicocelectomy in 5 of 12 studies. The present study followed the same pattern; varicocelectomy significantly increased sperm density in the post-operative followup.

The present study was compared with various previous studies regarding the effectiveness of laparoscopic varicocelectomy, which were shown below. Further studies with larger numbers of patients are needed to confirm the results.

\section{Age Incidence}

A total of 44 patients were included in our study. The youngest was 18 years old and the oldest was 42 years old. Mean age is 30 years. Our study is in comparison with Onozawa et al[11] study who has studied a total of 64 patients. In his study, the mean age is 34 years.

\section{Laterality}

Majority is seen on left side consisting of $77.2 \%$ of cases followed by bilateral varicocele of $18.2 \%$. Unilateral rightsided varicocele is extremely rare. A study conducted by Hitoshi et al, showed that left side varicocele is present in 53 patients among 64 patients with varicocele. Thus, in their study left-sided varicocele consisting of $79 \%$ of cases, which is almost equivalent to our study as shown in Table 8.

\section{Grading}

Total no. of cases is 44 , among them 8 patients have bilateral varicocele.

Thus, total no. of varicoceles became 52 of which 20 varicoceles are graded as II and 28 cases are graded as III and 4 varicoceles are graded as I. In the study conducted by Onozawa et al, among total 64 patients 10 patients are in grade I, 32 patients are grouped as grade II and 22 patients are grade III (Table 9).

Most of the symptomatic varicoceles are in grade II, III. In our study both grade II, grade III varicocele occupies a total of $92 \%$. Similarly, in Onozawa et al study both grades together consisting of $84 \%$.

\section{Pain Scale}

In Amagan A et al[12] study, complete success rate (Visual Analog Scale: 0-1) was found to be $79.2 \%$ (57/72), while failure (complete and partial failure) rate was $20.8 \%(15 / 72)$ (Table 10).

\section{Semen Analysis}

In our study, we have analysed the volume, sperm density and motility. We have noticed that there is no significant increase in volume of semen. But there is significant increase in sperm density and sperm motility (Table 11, 12). The results in sperm parameters in the study conducted by Gouda El-Labban on laparoscopic varicocelectomy are shown in Table 13.

Our study is in comparison with Gouda El-Labban[13] in terms of sperm density and sperm motility. Pregnancy rate of $14 \%$ is reported in our study. As sample size and duration of study is small, it is not compared to other study.

In our study out of 44 patients, 2 patients had post-op hydrocele and 2 patients had scrotal oedema. No incidence of recurrence of varicocele and atrophy of testis is seen.

\section{CONCLUSION}

Testicular varicoceles are an important disorder leading to significant symptoms like pain in some patients and associated with sub-fertility in others. Accurate diagnosis is important, as correct treatment may lead to resolution of symptoms and improvement in sperm count in sub-fertile patients.

Laparoscopic varicocelectomy is a minimally invasive procedure that is easy to perform with simple instruments. The clear visualisation and magnification provide control of the affected vessels, thus decreasing incidence of postoperative recurrence.

Compared to open varicocelectomy, laparoscopic varicocelectomy had shorter convalescence, early return to normal activities and less operative morbidity. The semen analysis performed showed that subjects with laparoscopic varicocelectomy had better quality semen.

\section{REFERENCES}

[1] Meacham RB, Townsend RR, Rademacher D, et al. The incidence of varicoceles in the general population when evaluated by physical examination, gray scale sonography and color doppler sonography. J Urol 1994;151(6):1535-8.

[2] Jarow JP. Effects of varicocele on male fertility. Hum Reprod Update 2001;7(1):59-64.

[3] Gorelick JI, Goldstein M. Loss of fertility in men with varicocele. Fertil Steril 1993;59(3):613-6.

[4] Lipshultz LI, Corriere JN. Progressive testicular atrophy in the varicocele patient. J Urol 1977;117(2):175-6.

[5] Lyon RP, Marshall S, Scott MP. Varicocele in childhood and adolescence: implication in adulthood infertility? Urology 1982;19(6):641-4.

[6] Haans LC, Laven JS, Mali WP, et al. Testis volumes, semen quality, and hormonal patterns in adolescents with and without a varicocele. Fertil Steril 1991;56(4):731-6.

[7] MacLeod J. Seminal cytology in the presence of varicocele. Fertil Steril 1965;16(6):735-57.

[8] Sharlip ID, Jarow J, Belker AM, et al. Male infertility best practice policy committee members and consultants: infertility. Linthicum, American Urology Association, 2001. 
[9] Al-Kandari AM, Shabaan H, Ibrahim HM, et al. Comparison of outcomes of different varicocelectomy techniques: open inguinal, laparoscopic, and subinguinal microscopic varicocelectomy: a randomized clinical trial. Urology 2007;69(3):417-20.

[10] Schlesinger MH, Wilets IF, Nagler HM. Treatment outcome after varicocelectomy. A critical analysis. Urol Clin North Am 1994;21(3):517-29.

[11] Onozawa M, Endo F, Suetomi T, et al. Clinical study of varicocele: statistical analysis and the results of longterm follow-up. Int J Urol 2002;9(8):455-61.
[12] Armağan A, Ergün O, Baş E, et al. Long-term effects of microsurgical varicocelectomy on pain and sperm parameters in clinical varicocele patients with scrotal pain complaints. Andrologia 2012;44(Suppl 1):611-4.

[13] El-labban G. Results of varicocele surgery: a comparison of laparoscopic and conventiential open high ligation. Egyptian Journal of Surgery 2011;30(1):14-8. 